\title{
Verifying Moisture Damage Impact in Asphalt Concrete with the Aid of Nondestructive Test NDT
}

\author{
Saad Issa Sarsam*, Nazar Sajad Kadium \\ Department of Civil Engineering, College of Engineering, University of Baghdad, Baghdad, Iraq \\ E-mail: saadisasarsam@coeng.uobaghdad.edu.iq (Corresponding author)
}

Received: 4 May 2020; Accepted: 27 May 2020; Available online: 20 June 2020

\begin{abstract}
One of the major concerns of pavement durability is its susceptibility to moisture damage. In this investigation, non-destructive test NDT has been implemented to detect the moisture damage issue. Asphalt concrete specimens were prepared using the traditional Marshall method for wearing, binder and asphalt stabilized base course. Specimens were traversed by ultrasound pulse velocity before and after practicing the moisture damage procedure. The variation of dynamic and elastic modulus before and after the moisture damage was considered and related to tensile strength ratio TSR. It was noted that the pulse velocity decline by $(11,11.2$ and $16.4) \%$ and the dynamic modulus declines by $(28,6.6$ and 28.5$) \%$ for asphalt concrete wearing, binder and base courses respectively after moisture damage. The elastic modulus exhibits no significant variation after moisture damage for wearing course while it declines by (9 and 11.7) \% for binder and base courses respectively after moisture damage. It was concluded that the elastic and dynamic moduli were unable to clearly distinguish the impact of moisture damage, whereas the Seismic modulus calculated from the Ultrasonic Pulse Velocity test was effective in distinguishing such impact. The linear equation obtained with good coefficient of determination can explain $74 \%$ of the variation in the seismic modulus after moisture damage.
\end{abstract}

Keywords: Moisture damage; NDT; Dynamic modulus; Asphalt concrete; Elastic modulus.

\section{Introduction}

The traditional mechanical testing methods require the installation of expensive load frame and instrumentation setup, moreover, they are time consuming. The ultrasonic pulse velocity UPV test usually requires lesser time, while the needed equipment is relatively inexpensive, [1]. Implementation of nondestructive testing (NDT) techniques for evaluation of asphalt concrete mixtures was investigated by several researchers through the past years. Some examples for such issue are the application of ultrasonic pulse wave velocity (UPV), impact resonance (IR), resonant column (RC), and acoustic emission (AE) tests for characterization of asphalt concrete strength quality, [2]. Terzi et al, [3] used the field and laboratory studies data to estimate the value of Marshall stability. Up to this aim, the pulse, Marshall properties, deflection, modulus of elasticity, density, and air void data were implemented as an input variable. The dynamic modulus of asphalt concrete mixtures was determined using the UPV by preparing Marshall specimens in the laboratory while considering the geometric density and bulk density of the specimens respectively. However, the experimental results data reveal that considering bulk density can give higher reliability to determine dynamic modulus of asphalt mix, [4]. The mechanical dynamic modulus test was implemented by Medina et al, [5] for determination of the dynamic moduli of hot-mix asphalt concrete (HMA). The dynamic moduli across multiple temperatures was determined using ultrasonic pulse velocity (UPV) test conducted on the same specimens. It was concluded that since the UPV test is considered simple as compared to the conventional dynamic modulus test, the test, in combination with either the Witczak or Hirsch model, may be used for estimation of the dynamic moduli of asphalt concrete at different reduced frequencies with a reasonable degree of accuracy. The primary cause of moisture damage in Hot Mix Asphalt mixture (HMA) is its cohesive failure and/or adhesive failure of aggregates and asphalt binder interface, [6]. Copeland et al., [7] described the water damage in asphalt concrete mixtures as the cohesive failure in the mastic, adhesive failure at the asphaltaggregate interface, and breakdown of aggregates. Birgisson et al, [8] stated that the UPV test can be used to indicate the damage in asphalt concrete specimens as well as to monitor and detect the changes in the integrity of mixtures. The UPV method appeared to provide sensitivity in detecting stripping damage effects for specimens with low air-void contents as reported by Barnes and Trottier, [9]. The sensitivity of the UPV test to the dynamic modulus and tensile strength determination was accounted for by the combined compressive and shear stresses comprising the surface wave motion. Pulse wave modulus testing is considered as a non-destructive testing method for field application to evaluate moisture damage-induced stiffness losses. 
The aim of this investigation is the implementation of NDT to detect the moisture damage issue. Specimens will be subjected to the ultrasonic pulse velocity traverse before and after practicing the moisture damage procedure. The variation of dynamic and elastic modulus before and after the moisture damage will be related to tensile strength ratio TSR.

\section{Materials and methods}

\subsection{Asphalt cement}

Asphalt cement binder implemented in this investigation was obtained from Dora refinery; the physical properties of the binder are shown in Table 1.

Table1. Physical Properties of Asphalt Cement

\begin{tabular}{lllc}
\hline \multicolumn{1}{c}{ Test procedure as per ASTM, [10] } & Result & Unit & SCRB, [11] Specification \\
\hline Penetration (25 $\left.{ }^{\circ} \mathrm{C}, 100 \mathrm{~g}, 5 \mathrm{sec}\right)$ as per ASTM D 5 & 43 & $1 / 10 \mathrm{~mm}$ & $40-50$ \\
Ductility (25 $\mathrm{C}, 5 \mathrm{~cm} / \mathrm{min})$. as per ASTM D 113 & 156 & $\mathrm{Cm}$ & $\geq 100$ \\
Softening point (ring \& ball). As per ASTM D 36 & 49 & ${ }^{\circ} \mathrm{C}$ & $50-60$ \\
\hline \multicolumn{2}{c}{ After Thin-Film Oven Test ASTM D-1754 } & & \\
Retained penetration of original, (\%) as per ASTM D 946 & 31 & $1 / 10 \mathrm{~mm}$ & $<55$ \\
Ductility at $25^{\circ} \mathrm{C}, 5 \mathrm{~cm} / \mathrm{min},(\mathrm{cm})$ as per ASTM D-113 & 147 & $\mathrm{Cm}$ & $>25$ \\
Loss in weight $\left(163^{\circ} \mathrm{C}, 50 \mathrm{~g}, 5 \mathrm{~h}\right)(\%)$ as per ASTM D-1754 & 0.175 & $\%$ & - \\
\hline
\end{tabular}

\subsection{Coarse and fine aggregates}

Coarse and fine aggregates implemented were locally available and usually used for pavement construction. The aggregates were obtained from Al-Nibaee quarry, Table 2 demonstrates the physical properties of aggregates.

Table 2. Physical Properties of Al-Nibaee Coarse and fine Aggregates

\begin{tabular}{lll}
\hline Property as per ASTM, [10] & Course Aggregate & Fine Aggregate \\
\hline Bulk Specific Gravity as per (ASTM C 127 and C 128) & 2.610 & 2.631 \\
Apparent Specific Gravity as per (ASTM C 127 and C 128) & 2.641 & 2.6802 \\
Percent Water Absorption as per (ASTM C 127 and C 128) & 0.423 & 0.542 \\
Percent Wear (Los-Angeles Abrasion) as per (ASTM C 131) & 20.10 & - \\
\hline
\end{tabular}

\subsection{Mineral filler}

The mineral filler used in this investigation is limestone dust and was obtained from Karbala. The physical properties of the filler are listed in Table 3.

Table 3. Physical Properties of Mineral Filler (Limestone dust).

\begin{tabular}{ll}
\hline Property & Value \\
\hline Bulk specific gravity & 2.617 \\
\% Passing Sieve No.200 & 94 \\
\hline
\end{tabular}

\subsection{Selection of aggregate gradation}

The selected aggregate gradation in this work follows the SCRB, [11] Specification for dense graded base, binder, and wearing courses, with (25, 19, and 12.5) mm nominal maximum size of aggregates respectively. Figure 1 exhibits the implemented aggregate gradations.

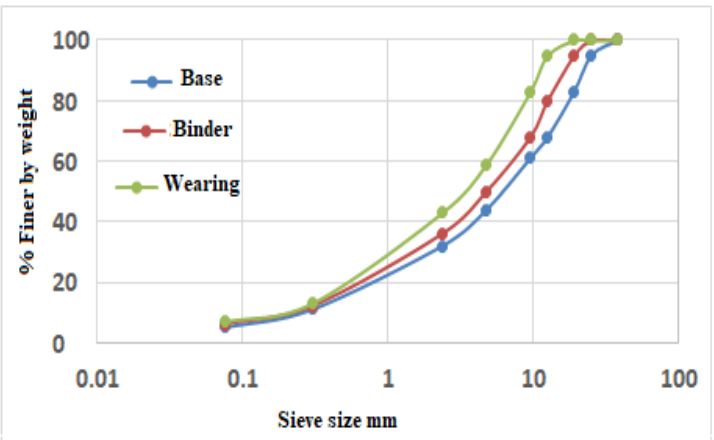

Figure 1. The implemented aggregate gradation according to SCRB, [11] 


\subsection{Preparation of hot mix asphalt concrete}

The aggregates were oven dried to a constant weight at $110^{\circ} \mathrm{C}$, then separated to different sizes by sieving, and stored separately in plastic containers. Coarse and fine aggregates were combined with mineral filler to meet the specified gradations for various asphalt concrete layers as per SCRB, [11] specifications shown in Figure 1. The combined aggregate mixture was heated to $150^{\circ} \mathrm{C}$ before mixing with asphalt cement. The asphalt cement was heated to the same temperature of $150^{\circ} \mathrm{C}$, then it was added to the heated aggregates to achieve the desired amount and mixed thoroughly using mechanical mixer for two minutes, until all aggregate particles were coated with thin film of asphalt binder. Marshall specimens were prepared in accordance with ASTM D1559, [10] using 75 blows of Marshall hammer on each face of the specimen for wearing and binder course and 50 blows on each face for asphalt stabilized base course as recommended by SCRB, [11]. The optimum asphalt content for each layer was determined. Specimens with optimum asphalt content and $0.5 \%$ of asphalt above and below the optimum have been prepared for each layer. Figure 2 shows part of the prepared specimens.

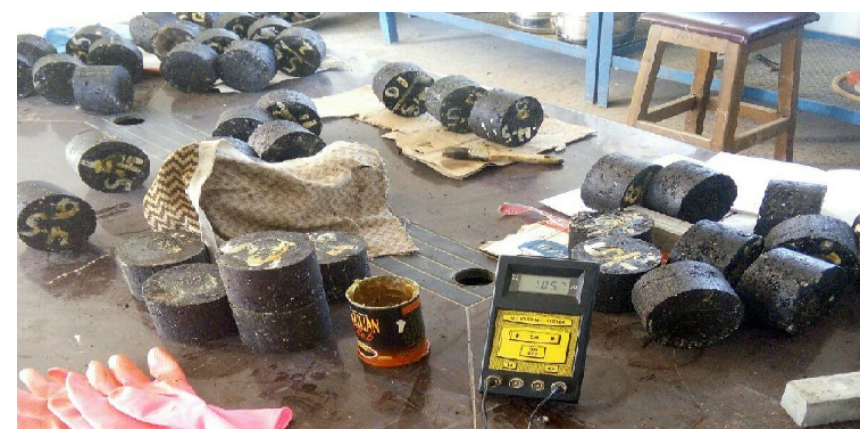

Figure 2. Part of The Prepared Specimens

\subsection{Ultrasonic pulse velocity measurement}

The use of the UPV test equipment is simple, quick, and nondestructive. The portable ultrasonic non-destructive digital indicating tester (Pundit) was implemented in this study. The device generates and receives ultrasound waves and has a digital display of the results, a frequency of $54 \mathrm{kHz}$ and accuracy of 0.1 were implemented throughout this investigation to measure the ultrasonic pulse velocity for the asphalt concrete specimens. The direct transmission arrangement technique was implemented in this investigation. The propagation of the low-strain mechanical waves generated by the equipment assesses the state of materials without causing damage. The pulser and receiver were placed on opposite parallel surfaces of the specimen as recommended by ASTM C597, [10]. Calibration of the pundit was conducted before testing to check the accuracy of the transit time measurements. This is achieved by the calibration with the reference bar. A thin layer of Vaseline oil was applied on the surface of the tested points to act as a couplet between the transducer and the asphalt concrete specimen's surface and to prevent dissipation of transmitted energy. The pulse transit path length of the specimen was measured accurately, and the time of its traversing was recorded. The distance between the transducers, which is equal to the thickness of the specimen, was divided by the time measured to calculate the ultrasonic pulse waves velocity. Eight readings were performed and averaged for each specimen. The ultrasonic pulse velocity test setup is demonstrated in Figure 3.

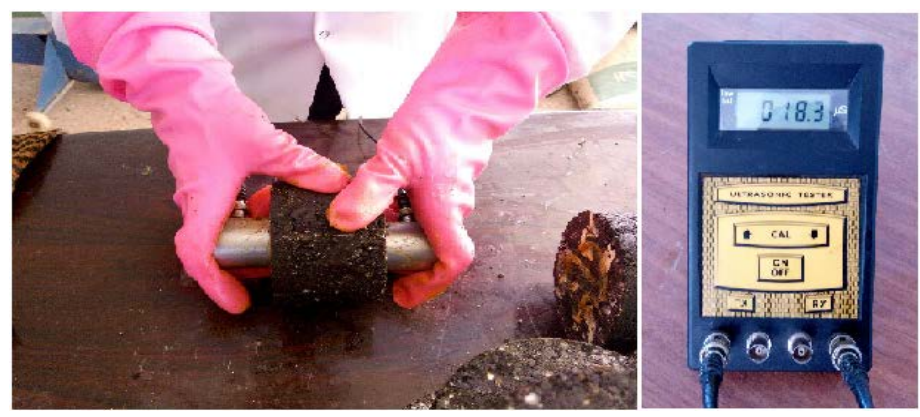

Figure 3. Ultrasonic pulse velocity Measurement in process

\subsection{Testing for resistance to moisture damage}

The asphalt concrete specimens have practiced moisture damage as per the procedure described by AASHTO, [12] and Sarsam and Alwan, [13]. The specimens were divided into two groups, the first group was denoted as unconditioned specimens which was tested for ITS at $25^{\circ} \mathrm{C}$. The second group of Asphalt concrete specimens were 
immersed in a water bath at $25^{\circ} \mathrm{C}$ and subjected to saturation under a vacuum pressure of $3.74 \mathrm{kPa}$ for ten minutes, then the specimens were removed from the water bath and stored in a deep freezer for 16 hours at $(-18)^{\circ} \mathrm{C}$. Afterword, Specimens were withdrawn from the deep freezer and allowed for thawing for 120 minutes in air, then transferred to a water bath and stored for 120 minutes at $60^{\circ} \mathrm{C}$. Specimens were denoted as conditioned specimens then stored at $25^{\circ} \mathrm{C}$ for 120 minutes before testing for ITS. Figure 4 demonstrates the specimens under moisture damage process.

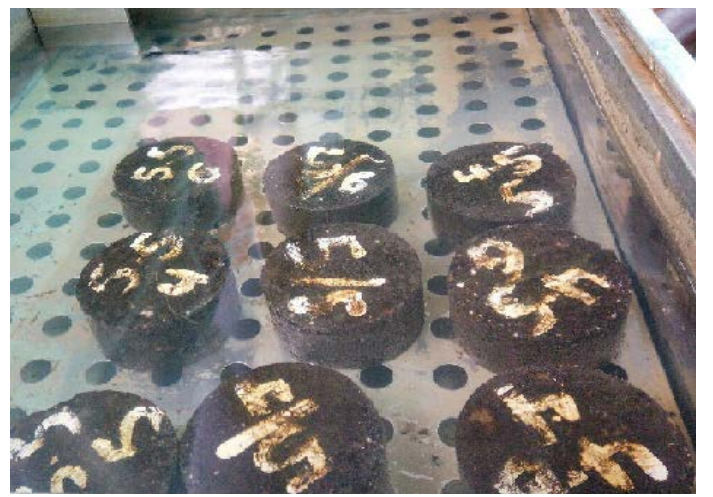

Figure 4. Specimens Under Moisture Damage Process

\subsection{Indirect tensile strength test ITS}

The indirect tensile strength test was conducted following the procedure of (ASTM D6931, [10]; Marshall Specimens were stored in the water bath at $25^{\circ} \mathrm{C}$ for 30 minutes and then each specimen was subjected to ITS test after getting centered on the vertical diametrical plane between the two parallel loading strips of $12.7 \mathrm{~mm}$ width. Vertical compression load was applied at a loading rate of $50.8 \mathrm{~mm} / \mathrm{min}$ by Versa tester machine until the dial gage reading reached the maximum load resistance. The indirect tensile strength (ITS) was calculated using the following equation (1), as per (ASTM D4123, [10].

$$
\operatorname{ITS}=2000 * P / \pi * T * D
$$

Where, ITS = indirect Tensile Strength $(\mathrm{kPa}) ; \mathrm{P}=$ maximum load resistance at failure; $\mathrm{D}=$ diameter of specimen $(\mathrm{mm}) ; \mathrm{T}=$ thickness of specimen $(\mathrm{mm})$.

\subsection{Determination of seismic elastic, and dynamic modulus of asphalt concrete}

In this study, $54 \mathrm{kHz}$ frequency ultrasound wave was implemented to test asphalt concrete specimens. Such frequency was recently employed by Arabani and Kheiry, [14]. Since asphalt concrete is a viscoelastic material, the theory of elasticity can be used, and the displacements and corresponding strains are very small while the actual movements are very short in duration. This is a reasonable assumption since the test was conducted at $25^{\circ} \mathrm{C}$. For simplicity, the asphalt concrete mixture can be assumed as homogenous and isotropic solid, [8] and [15]. The ultrasonic device consists of a pulse generator and a timing circuit, coupled with piezoelectric transmitting and receiving transducers. In the UPV test, a pulse wave emitted by a transmitter which propagates through the material while it is detected by a receiver. The velocity of the ultrasonic pulse is related to the modulus of the asphalt concrete. The Seismic Modulus can be determined using equation 2, [16] and [17].

$$
\mathrm{E}_{\mathrm{v}}=1.274 \times 10^{9} \times \frac{W H}{(D t v) 2} \times \frac{(1+v)(1-2 v)}{(1-v)}
$$

where, $\mathrm{EV}=$ Seismic modulus (MPa); $\mathrm{H}=$ Height of specimen (mm); W = Weight of specimen (kg); $\mathrm{D}=$ Dimeter of specimen (mm); tv = Average travel time (microseconds); $\mathrm{v}=$ Poisson ratio (0.4).

The Dynamic Modulus of asphalt concrete can be obtained by the pulse velocity technique as stated by Malik, [18]. An electrical timing unit measures the time taken for a pulse to travel through the asphalt concrete with an accuracy of $\pm 0.1 \mu$ seconds. Once this time is known, the dynamic modulus can be calculated by equation 3 .

$$
\mathrm{E}=\left(\mathrm{VC} \mathrm{C}^{2} \mathrm{r}\right) / \mathrm{g}
$$

where, $\mathrm{E}=$ Dynamic modulus of elasticity $(p \mathrm{sf}) ; V_{\mathrm{c}}=$ Longitudinal wave velocity $(\mathrm{ft} / \mathrm{second}) ; g=$ Acceleration due to gravity $\left(f \mathrm{t} / \mathrm{sec}^{2}\right) ; \gamma=$ Unit weight of the sample $\left(l \mathrm{~b} / f \mathrm{t}^{3}\right)$. 
The Elastic Modulus is calculated From the Pulse Velocity, the pulse velocity $\mathrm{V}$ of longitudinal stress waves in the material is related to its elastic properties and density according to Eq. (4) and (5), [5].

$$
\begin{aligned}
& V=\sqrt{\left(\frac{(E(1-V))}{\rho(1+V)(1-2 V)}\right)} \\
& \mathrm{E}=\left(\left(\mathrm{VC}^{2} \rho(1+\mathrm{V})(1-2 \mathrm{~V})\right) /(1-\mathrm{V})\right.
\end{aligned}
$$

where, $\mathrm{V}=$ pulse velocity of longitudinal stress waves in meters per second; $\mathrm{E}=$ elastic modulus in (Gpa); $v=$ dynamic Poisson's ratio; $\rho=$ density in $\mathrm{kg} / \mathrm{m}^{3}$.

\section{Results and discussions}

As demonstrated in Figure 5 for wearing course asphalt concrete, the pulse velocity was in the range of (3.13.9) before moisture damage and decline by $5.7 \%$ after moisture damage to the range between (3.1-3.5) $\mathrm{mm} /$ microseconds. This could be attributed to the stripping of asphalt film surrounding the aggregate particles which decreases the adhesion between asphalt and aggregate and initiate more voids in the mixture. This was further supported by the reduction in elastic modulus from a range of (10-17) Gpa to (12-17) Gpa after moisture damage. This may be attributed to the reduction in cohesion between aggregate particles due to the stripping action. On the other hand, the reduction in dynamic modulus as well as the pulse velocity is more pronounced after moisture damage as shown the Figure 5. The dynamic modulus declines by $28 \%$ and the pulse velocity decreased by $11 \%$ after moisture damage. Similar finding was reported by Arepalli, [19].

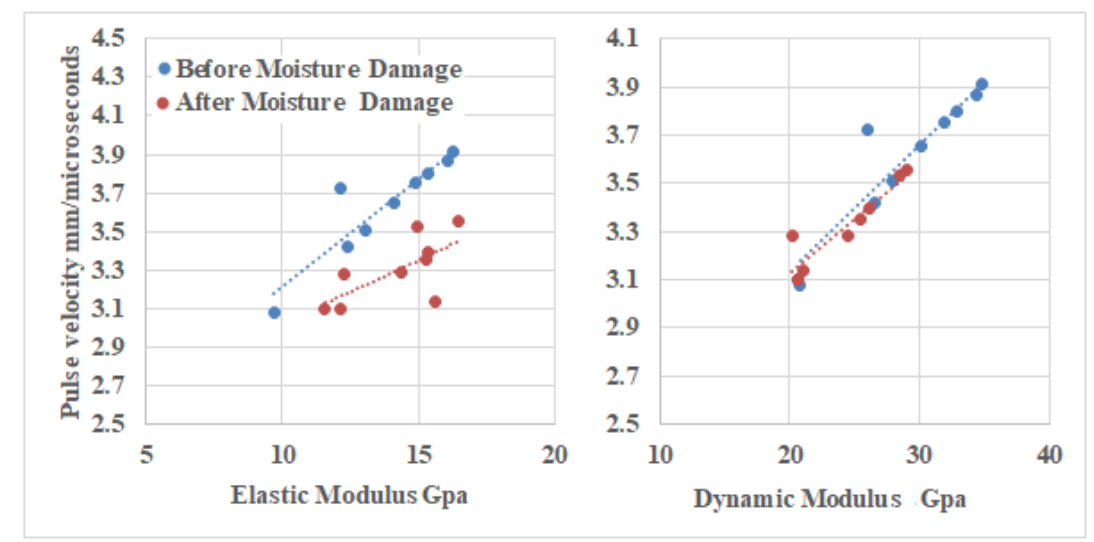

Figure 5. Moisture Damage of Wearing Course

Figure 6 exhibit the influence of moisture damage on modulus and pulse velocity of asphalt concrete binder course. It can be noted that the pulse velocity decreases by $11.2 \%$ while the elastic modulus declines by $9 \%$ after moisture damage. On the other hand, the dynamic modulus decreases by $6.6 \%$ after moisture damage. Such behavior of the impact of moisture damage on binder course as compared to wearing course may be attributed to the coarser gradation adopted in binder course. Such findings agree well with the work reported by Arabani and Kheiry, [15].
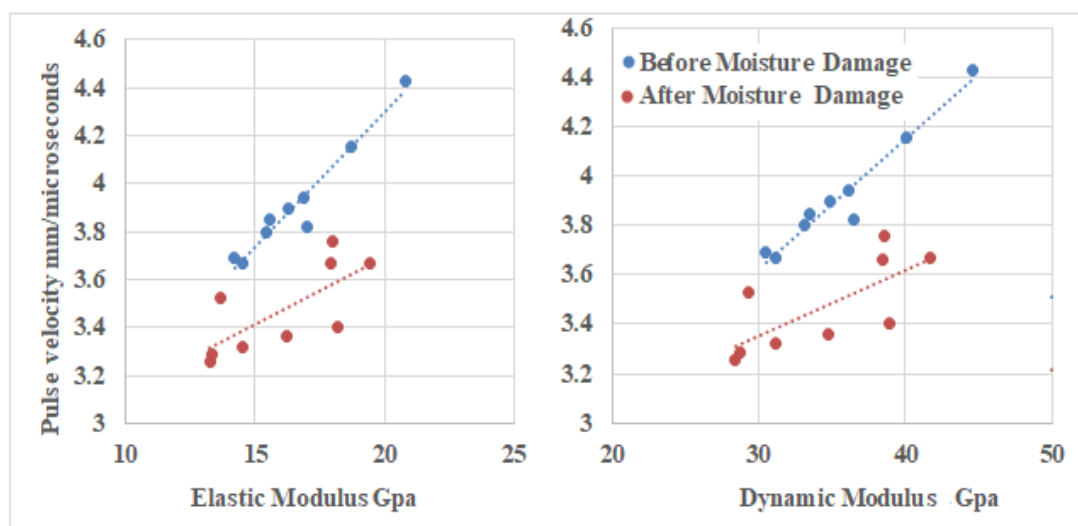

Figure 6. Moisture Damage of Binder Course 
Figure 7 exhibit the impact of moisture damage on modulus and pulse velocity of asphalt concrete base course. It can be noted that the pulse velocity decreases by $16.4 \%$ while the elastic modulus declines by $11.7 \%$ after moisture damage. On the other hand, the dynamic modulus declines by $28.5 \%$ after moisture damage. Such behavior of the impact of moisture damage on base course as compared to wearing and binder courses may be attributed to the coarser gradation adopted in base course. Such findings agree well with the work reported by Tarefder and Yousefi, [20].

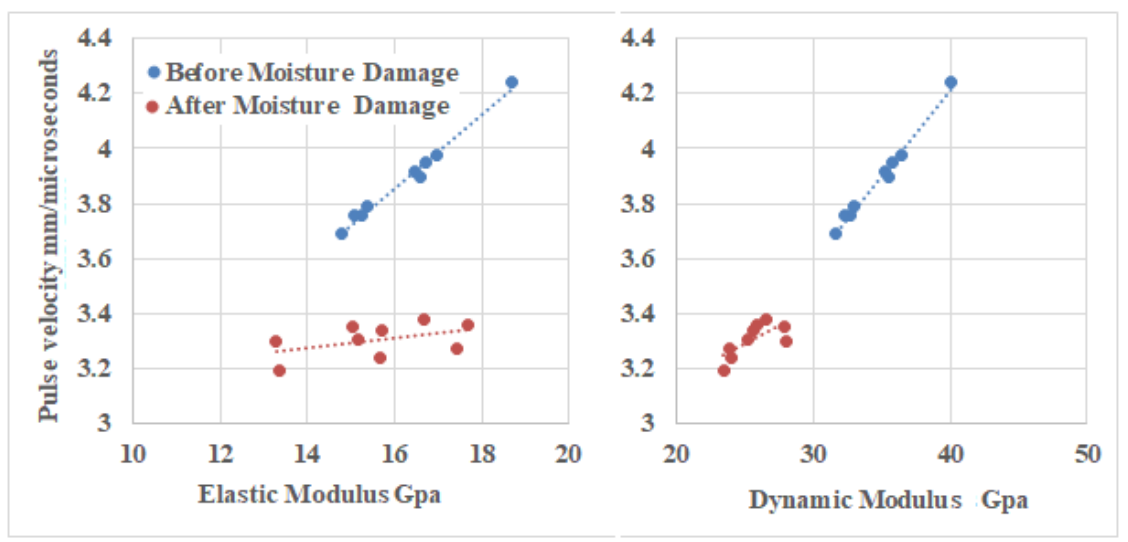

Figure 7. Moisture Damage of Base Course

The elastic and dynamic moduli were unable to clearly distinguish the impact of moisture damage, whereas the Seismic modulus obtained from the Ultrasonic Pulse Velocity test was effective in distinguishing such impact. Figure 8 exhibit the influence of moisture damage on pulse velocity and seismic modulus. The variation in ultrasonic pulse velocity when testing the specimens before and after practicing moisture damage was plotted on the (y-axis) and the variation in seismic modulus when calculated for specimens before and after practicing moisture damage was plotted on the (x-axis). The linear equation (equation 6) obtained with good coefficient of determination can explain $74 \%$ of the variation in the modulus after moisture damage. It can be noted that Wearing and binder courses mixtures have better stripping resistance than base course mixture for the same aggregate and binder types. This could be attributed to the variations in asphalt content and gradation. Similar finding was reported by Khedaywi and Al Kofahi, [21].

$$
\mathrm{Y}=0.0901 \mathrm{X}-0.2203
$$

where, $\mathrm{Y}=$ Variation in pulse velocity before and after moisture damage; $\mathrm{X}=$ Variation in Seismic Modulus before and after moisture damage.

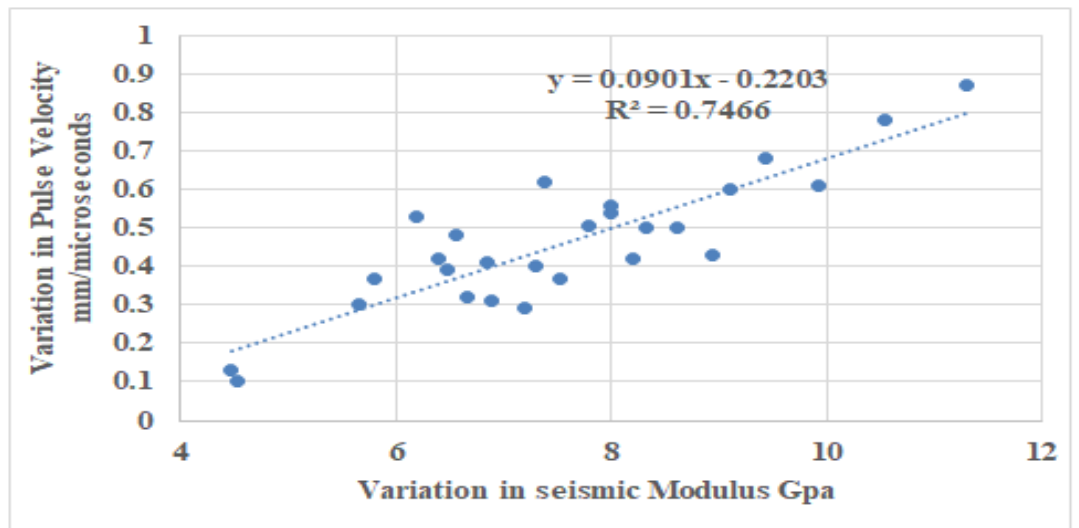

Figure 8. Impact of Moisture Damage on Pulse velocity and Seismic Modulus

\section{Conclusions}

Based on the limitations of materials employed and the testing program, the following conclusions can be drawn.

1) For asphalt concrete wearing course, the dynamic modulus declines by $28 \%$ and the pulse velocity decreased by $11 \%$ after moisture damage, while the elastic modulus exhibits no significant variation after moisture damage. 
2) For asphalt concrete binder course, pulse velocity decreases by $11.2 \%$ while the elastic modulus declines by $9 \%$ after moisture damage. The dynamic modulus decreases by $6.6 \%$ after moisture damage.

3) For asphalt concrete base course, the pulse velocity decreases by $16.4 \%$ while the elastic modulus declines by $11.7 \%$ after moisture damage. The dynamic modulus declines by $28.5 \%$ after moisture damage.

4) The elastic and dynamic moduli were unable to clearly distinguish the impact of moisture damage, whereas the Seismic modulus obtained from the Ultrasonic Pulse Velocity test was effective in distinguishing such impact.

5) The linear equation obtained with good coefficient of determination can explain $74 \%$ of the variation in the seismic modulus after moisture damage.

6) Wearing and binder courses mixtures have better stripping resistance than base course mixture.

\section{References}

[1] Goel A., Das A. Nondestructive testing of asphalt pavements for structural condition evaluation: a state of the art. Nondestructive Testing and Evaluation. 2008; 23(2): 121-140.

[2] Tavassoti-Kheiry P., Boz I., Chen X., Solaimanian M. Application of ultrasonic pulse velocity testing of asphalt concrete mixtures to improve the prediction accuracy of dynamic modulus master curve. Proceedings, Airfield and Highway Pavements. 2017, ASCE.

[3] Terzi S., Karasahin M., Gokova S., Tahta M., Morova N., Uzun I. Asphalt concrete stability estimation from non-destructive test methods with artificial neural networks. Neural Computer \& Applications. 2013; 23:989997.

[4] Majhi D., Karmakar S., Roy T. Reliability of ultrasonic pulse velocity method for determining dynamic modulus of asphalt mixtures. ICEMS 2016, Materials Today: Proceedings 4. 2017: 9709-9712.

[5] Medina. J. R., Underwood B. S., Michael Mamlouk M. Estimation of asphalt concrete modulus using the ultrasonic pulse velocity test. Journal of Transportation Engineering, Part B: Pavements, ASCE. 2018; 144(2): 04018008.

[6] Airey, G. D., Choi, Y.-K. State of the art report on moisture sensitivity test methods for bituminous pavement materials. Road Materials and Pavement Design. 2002;3(4): 355-372.

[7] Copeland, A. R., Kringos, N., Youtcheff Jr, J. S., Scarpas, T. Measurement of aggregate-mastic bond strength in presence of moisture: combined experimental-computational study. Proc., Transportation Research Board 86th Annual Meeting. 2007.

[8] Birgisson, B., Roque, R., Page, G. Ultrasonic pulse wave velocity test for monitoring changes in hot-mix asphalt mixture integrity from exposure to moisture. Transportation Research Record: Journal of the Transportation Research Board. 2003;1832:173-181.

[9] Barnes, C. L., Trottier, J.-F. Evaluating laboratory-induced asphalt concrete moisture damage using surface waves. International Journal of Pavement Engineering. 2010;11(6): 489-497.

[10] ASTM, Road and Paving Materials, Annual Book of ASTM Standards, Volume 04.03, Standard test method for pulse velocity through concrete. ASTM C597-09, 2009.American Society for Testing and Materials, West Conshohocken, USA.

[11] State Commission of Roads and Bridges SCRB. Standard specification for roads \& bridges, 2003. Ministry of Housing \& Construction, Iraq.

[12] AASHTO, Standard specification for transportation materials and methods of sampling and testing, American Association of State Highway and Transportation Officials, 14th Edition, 2013, Part II, Washington, D.C.

[13] Sarsam S., Alwan A. Properties of super pave asphalt concrete subjected to impact of moisture damage. Journal of Engineering. 2015;21(1):1-14.

[14] Arabani M., Kheiry T.P. A new method for determination stiffness modulus of HMA mixtures. ISSA World Congress and International Seminar on Asphalt Pavement Maintenance Technologies, China. 2006.

[15] Arabani M., Kheiry T.P. Evaluating the use of ultrasonic pulse velocity test for determination dynamic elastic modulus of HMA mixtures. Asphalt Institute of Iran, 3rd national Congress on Asphaltic Materials. 2006.

[16] TDOT. Quality management of flexible pavement layers with seismic methods: test methods. Texas Department of Transportation and the Federal Highway Administration Project Number 5-1735-01. 2006.

[17] Gudmarsson A. Laboratory seismic testing of asphalt concrete. Licentiate Thesis KTH Royal Institute of Technology, School of Architecture and Built Environment, Department of Transport Science Division of Highway and Railway Engineering SE-100 44, 2012, Stockholm.

[18] Malik A. Evaluation of testing procedure for dynamic modulus of asphalt concrete. International Journal of Scientific \& Engineering Research.2015; 6(4): 1647.

[19] Arepalli U. M. A study of moisture induced material loss of hot mix asphalt (HMA). PhD Dissertation. Worcester Polytechnic Institute. India. 2018

[20] Tarefder R. A. Yousefi S. S. Laboratory evaluation of moisture damage in asphalt. Can. J. Civ. Eng. 2012;39: 104-115. 
[21] Khedaywi T. Kofahi N. Utilization of the resilient modulus test to predict stripping of asphalt concrete mixture. International Journal of Civil Engineering and Technology (IJCIET). 2019;10(05):706-726.

(C) 2020 by the author(s). This work is licensed under a Creative Commons Attribution 4.0 International License (http://creativecommons.org/licenses/by/4.0/). Authors retain copyright of their work, with first publication rights granted to Tech Reviews Ltd. 